\title{
The Role of Intrinsic and Extrinsic Rewards in Committing Violence During Combat: A Cross-Sectional Study With Former Combatants in the DR Congo
}

\author{
Haer, Roos ; Hermenau, Katharin ; Elbert, Thomas ; Moran, James K ; Hecker, Tobias
}

\begin{abstract}
It has been postulated that the violent behavior that characterizes armed conflict is reinforced by the possibility of receiving rewards. The present study examined the potential influence of two types of rewards in an ongoing setting of conflict: extrinsic and intrinsic rewards. Former combatants active in the Democratic Republic of the Congo $(\mathrm{N}=198)$ were interviewed and questioned about the way they were recruited, the offenses they committed during combat, their level of perceived intrinsic rewards (i.e., appetitive perception of violence), and the number of received extrinsic rewards during their time in the armed group (e.g., money, extra food, alcohol, or drugs). A moderated multiple regression analysis showed that the number of received extrinsic rewards and the level of intrinsic rewards were significantly positively related to the number of different types of offenses committed. In contrast to our expectations and previous findings, the recruitment type (forced conscription vs. voluntary enlistment) did not moderate this relation. Our findings suggest that both types of rewards play a role in committing violence during combat. We suggest, therefore, that reintegration programs should not only consider the influence of extrinsic rewards, but also need to address the influence of intrinsic rewards to counter violent behavior among former combatants.
\end{abstract}

DOI: https://doi.org/10.1002/ab.21684

Posted at the Zurich Open Repository and Archive, University of Zurich

ZORA URL: https://doi.org/10.5167/uzh-127556

Journal Article

Accepted Version

Originally published at:

Haer, Roos; Hermenau, Katharin; Elbert, Thomas; Moran, James K; Hecker, Tobias (2017). The Role of Intrinsic and Extrinsic Rewards in Committing Violence During Combat: A Cross-Sectional Study With Former Combatants in the DR Congo. Aggressive Behavior, 43(3):241-250.

DOI: https://doi.org/10.1002/ab.21684 


\section{AGGRESSIVE BEHAVIOR}

The role of intrinsic and extrinsic rewards in committing violence during combat: A cross-sectional study with former combatants in the DR Congo

\begin{tabular}{|r|l|}
\hline Journal: & Aggressive Behavior \\
\hline Manuscript ID & AB-15-248.R2 \\
\hline Wiley - Manuscript type: & Research Article \\
\hline Complete List of Authors: & $\begin{array}{l}\text { Haer, Roos; University of Konstanz, Department of Politics and } \\
\text { Management; vivo international } \\
\text { Hermenau, Katharin; University of Konstanz, Psychology; vivo international } \\
\text { Elbert, Thomas; University of Konstanz, Psychology; vivo international } \\
\text { Moran, James; Universitat Konstanz Fachbereich Psychologie } \\
\text { Hecker, Tobias; University of Zürich, Department of Psychology; vivo } \\
\text { international }\end{array}$ \\
\hline Keywords: & aggression, appetitive perception of violence, rewards, military, violence \\
\hline
\end{tabular}


REWARDS AND VIOLENCE

The role of intrinsic and extrinsic rewards in committing violence during combat: $A$ cross-sectional study with former combatants in the DR Congo

Roos Haer ${ }^{1,2}$, Katharin Hermenau ${ }^{2,3}$, Thomas Elbert ${ }^{2,3}$, James K. Moran ${ }^{3}$ and Tobias Hecker $^{2,4}$

${ }^{1}$ Department of Politics and Public Administration, University of Konstanz, 78457 Konstanz, Germany

2 vivo international, www.vivo.org

${ }^{3}$ Department of Psychology, University of Konstanz, 78457 Konstanz, Germany

${ }^{4}$ Department of Psychology, University of Zurich, 8050 Zurich, Switzerland

Acknowledgements: This research was supported by the NGO vivo international and by the Deutsche Forschungsgemeinschaft (DFG). The authors declare that they have no conflict of interest. We are grateful to all the former combatants for their readiness to participate. We thank Maggie Schauer, Anna Maedl, Harald Hinkel, Heike Riedke, Roger Buhendwa Zashurwa, Ben Ombeni Cigolo, and Flory Barhimanya Kahisa for their support with data collection and logistics. We also thank the staff of the NGO Equipe d'Education et d'Encadrement des Traumatisés de Nyiragongo and of the demobilization camp of the United Nations for all their help.

Corresponding author: Tobias Hecker, Department of Psychology, University of Zurich, Binzmuehlestr. 14/17, 8050 Zurich, Switzerland. Tel. +41 446357 305, E-mail: t.hecker@,psychologie.uzh.ch 


\section{Abstract}

It has been postulated that the violent behavior that characterizes armed conflict is reinforced by the possibility of receiving rewards. The present study examined the potential influence of two types of rewards in an ongoing setting of conflict: extrinsic and intrinsic rewards. Former combatants active in the Democratic Republic of the Congo $(N=198)$ were interviewed and questioned about the way they were recruited, the offenses they committed during combat, their level of perceived intrinsic rewards (i.e., appetitive perception of violence), and the number of received extrinsic rewards during their time in the armed group (e.g. money, extra food, alcohol or drugs). A moderated multiple regression analysis showed that the number of received extrinsic rewards and the level of intrinsic rewards were significantly positively related to the number of different types of offenses committed. In contrast to our expectations and previous findings, the recruitment type (forced conscription vs. voluntary enlistment) did not moderate this relation. Our findings suggest that both types of rewards play a role in committing violence during combat. We suggest, therefore, that reintegration programs should not only consider the influence of extrinsic rewards, but also need to address the influence of intrinsic rewards to counter violent behavior among former combatants.

Keywords: aggression, appetitive perception of violence, rewards, violence, military 
REWARDS AND VIOLENCE

\section{Background}

Severe forms of violence characterize current conflicts. For instance, many combatants active in the Democratic Republic of the Congo (DRC) intentionally harm their victims with machetes and other weapons and frequently rape them, either before or after their mutilation (Human Rights Watch, 2014). Also in other conflicts, such as in Rwanda, Liberia and Sierra Leone, many people have had their arms, ears, legs, noses, genitalia, and Achilles tendon deliberately mutilated (New York Times, 1999).

Many variables are likely to combine to explain these acts, from broader political, economic and sociological influences, to individual psychological and biological ones. Political variables include, for example, the influence of military weakness (Wood, 2010), military strategy (Kalyvas, 1999), or measures to destroy the support base of the opposing party (Valentino, Huth, \& Balch-Lindsay, 2004). Others have focused on psychological influences, such as dehumanization of the enemy (Grossman, 1995; Staub, 2001, 2006) or initiation rites in armed groups (Engen, 2008; Gibson, 1991). Again others have examined the idea that combatants might also be reinforced to engage in violent behavior by incentivizing such behavior with rewards (Littman \& Paluck, 2015). They have primarily focused on the influence of extrinsic rewards, such as money, access to sexual partners, or social status. However, few researchers have considered the influence of intrinsic pleasure in the aggressive act itself, which is a fundamental component of the psychology of violence (Elbert, Weierstall, \& Schauer, 2010; Nell, 2006).

Aggression is commonly defined as any behavior towards another individual that includes the intention to harm (Berkowitz, 1993), with violence as the most extreme manifestation of human aggression (Anderson \& Bushman, 2002). The function of aggression falls generally into two main categories: reacting to danger and resource competition (Archer, 1988, 2009). Around these functions one observes different cognitive, 
emotional, physiological and behavioral responses in the aggression types: hostile and instrumental aggression (e.g., Anderson \& Bushman, 2002; Kempes, Matthys, De Vries, \& Van Engeland, 2005). Hostile aggression is also known as reactive or affective aggression and can be seen as being impulsive, driven by anger, and occurring as a reaction to some perceived provocation or threat (e.g., Anderson \& Bushman, 2002; Bushman \& Anderson, 2001). In contrast, instrumental aggression is a more cognitively controlled response, prompted by its anticipated benefit and rewards, such as access to sexual partners (WeekesShackelford, Shackelford, \& Buss, 2003), improved status (Daly \& Wilson, 1996; Shackelford, 2005), or access to resources (Kruger \& Nesse, 2004).

The pure separation of these forms of aggression is, however, questionable (Bushman \& Anderson, 2001), as they highly correlate within an individual or as a function of the situation (Card \& Little, 2006) and often occur simultaneously (Archer, 2009; Kempes et al., 2005). Consequently, explaining aggressive and violent behavior in humans requires measuring the influence of various (intertwined) variables simultaneously (e.g., Anderson \& Bushman, 2002; Archer, 2009). For instance, Eisner (2009) emphasized the influence of the sex distribution of people involved in fighting (mostly men); the approximate age at which people are most likely to engage in violence (about 18 to 35); essential goals over which fights are fought (material resources, power, and sex); situations that are prone to violence (e.g., humiliations in the presence of others); individual characteristics associated with violence (e.g., courage and risk-seeking); and emotional processes involved in violent encounters (e.g., arousal and anger). Although we do not deny the importance of all these factors (and their interaction) in explaining aggressive and violent behavior, in the specific context of the ongoing conflict in the DRC, this interdisciplinary study focused on the explanatory value of one particular motivational factor, i.e. the role of rewards as an incentive for committing violent acts. 
Studies conducted in the field of international relations (i.e., conflict research) have mainly focused on the explanatory power of extrinsic rewards. These can be defined as rewards that are tangible and visible to others (Mottaz, 1985) and are as numerous as the number of objects that people desire. Commanders in armed groups can, for instance, offer money and goods such as food, clothing, better housing, sexual partners, territory, drugs, weapons, and access to natural resources (e.g., Gat, 2000; Kruger \& Nesse, 2004; Palmer \& Tilley, 1995; Weekes-Shackelford et al., 2003; Weinstein, 2007). At the same time, they may also condone or actively encourage looting as a way to provide additional extrinsic rewards (Collier \& Hoeffler, 2004) or withdraw extrinsic rewards as a form of punishment for failing to participate in violence (Littman \& Paluck, 2015). An important advantage connected to the use of these extrinsic rewards, is that they not only incentivize violent behavior of individual combatants (Humphreys \& Weinstein, 2006) but distributing them can also overcome the well-known collective action problem that many armed groups face, i.e. motivating people to join the group even if it can result in death or harm (e.g., Keen, 2000).

In contrast to instrumental aggression that is extrinsically rewarded, relatively little attention has been given to the influence of intrinsic rewards (i.e. non-tangible rewards, such as self-esteem, the feeling of belonging to a particular group) in motivating aggressive behavior in conflict settings (e.g., Glowacki \& Wrangham, 2013; Opp, 1986; Wessells, 1997). This lack of research might be partly explained by the fact that some scholars have problems measuring these so-called soft incentives (Opp, 1986). The study conducted by Haer, Banholzer, Elbert, and Weierstall (2013) forms an important exception. They revealed that not only extrinsic but also intrinsic rewards in the form of comradery with fellow combatants in the same unit were associated with positive emotions linked to aggressive behavior. A significant limitation of this study, however, is that Haer et al. (2013) ignored the fact that perpetrating violence itself may be perceived as rewarding in humans (Nell, 2006). 
Arguments on the influence of this appetitive perception of violence are based in an evolutionary point of view, in which instrumental aggression can be reframed in terms of survival and reproductive value, for example as a co-opting strategy concerning the distribution of resources, as a way of inflicting costs on same-sex rivals, or as a way to negotiate status and power within a social group (Buss \& Shackelford, 1997). Through the access to resources and sexual partners, aggressive behavior is not only favored during evolutionary adaptation but it is also rewarded and reinforced by social learning (Bandura, 1978; Gibson, 1991). One important implication coming from this is that insofar as aggression had an instrumental function in the course of human evolution, then those people capable of enjoying it would have had an advantage, both in terms of survival and sexual selection (Nell 2006). In this way of thinking, the aggressive act in itself becomes enjoyable above and beyond its original instrumental function (e.g., Hecker, Hermenau, Maedl, Elbert, \& Schauer, 2012; Weierstall, Schalinski, Crombach, Hecker, \& Elbert, 2012).

In this study, we argue that this appetitive perception of violence describes one (of the many) intrinsically, rewarding mechanism to act aggressively and violently in conflict settings. However, the relation between extrinsic rewards, these intrinsic rewards and other aspects influencing the level of aggression, such as the age and the way in which the combatants are recruited, is so-far unknown. Some studies on former combatants of armed groups showed, for instance, meaningful psychological differences between those combatants who were forcibly recruited and those who voluntary enlisted, with the latter reporting higher levels of appetitive perception of violence (Haer et al., 2013; Hecker, Hermenau, Maedl, Hinkel, et al., 2013; Weierstall, Bueno Castellanos, Neuner, \& Elbert, 2013). Yet, a 'voluntary' decision to join the militias is made in the context of a variety of push and pull factors, e.g., desire to avenge one's community/tribe or lack of prospects at home, and the promise of regular meals and income in the militia (United Nations, 2016). Haer et al. (2013), 
for instance, showed that the relationship between the types of rewards and aggression might be driven by this particular factor: the level of appetitive perception of violence reported by abducted combatants was more strongly influenced by material rewards than those that joined on a voluntary basis. One explanation may be that voluntarily enlisted combatants were more likely to be intrinsically motivated as they fought to defend their families, villages and own ethnic group. Hence, they did not need material rewards in order to positively perceive the perpetration of violence. At the same time, forcibly recruited combatants usually did not have a high level of intrinsic motivation to participate in violence in the first place. They may be more motivated by receiving direct tangible goods for their behavior.

Another potential influence on the relationship between the two types of rewards and aggression is the combatant's age at the time of the recruitment. Though one can postulate individual differences in different forms of aggression, this in part arises by timing of exposure to environmental factors. A recent study of child soldiers showed levels of appetitive perception of violence increasing as a function of the age of exposure to violence, with boys recruited at ages 16-17 showing particularly strong appetitive perception of violence (Köbach \& Elbert, 2015). Moreover, previous research revealed a significant relation between the level of appetitive perception of violence and the age at recruitment, with child soldiers reporting higher levels of appetitive perception of violence (Hecker et al., 2012; Weierstall et al., 2013).

The following study investigated the relative influence and interrelation of intrinsic rewards (i.e., the appetitive perception of violence) and extrinsic rewards (e.g., received money, food, other goods, etc.) as motivational factors of violent behavior in a large sample of former combatants. We also investigated whether these relations were differentially affected by means of recruitment of the combatants. To be more precise, we expected that forcibly recruited combatants would show a stronger relationship between extrinsic rewards 
and committed violent acts, whereas combatants who enlisted voluntarily would show a stronger relation between intrinsic rewards and committed violent acts. Additionally, we predicted that the age at recruitment would also play an important role.

\section{Method}

\section{Setting}

In the analyses, we used information gathered from a sample of former combatants from various armed groups active in the eastern provinces of the DRC. This country has been trapped in an ongoing cycle of war and violence for more than two decades (Elbert et al., 2013). Following the Rwandan genocide in 1994, at least one million people fled to today's eastern DRC (Prunier, 2009). In reaction to the creation of new armed groups among this refugee population, Rwandan and Ugandan armies entered the DRC in 1996 launching the First Congo War, which formally ended in 1998. The Second Congo War, also known as Africa's Great War, was waged between 1998 and 2002. Despite the significant United Nations (UN) peacekeepers' presence and the new peace agreements in 2008 and 2009, fighting among various armed groups is still continuing (Elbert et al., 2013).

\section{Participants}

In total, 224 interviews were conducted. Only former combatants who reported combat experience were included in the analyses. Additionally, ten interviews could not be completed due to the short stay of the ex-combatant in the demobilization camp. Consequently, they were excluded from all analyses, resulting in a total sample of $N=198$. All participants were male and had a mean age of 24.41 years $(S D=7.00$; range: $15-50)$. Three quarters of participants were born in the DRC, while the others originate from the neighboring country Rwanda. On average, they reported 4.98 years of formal education (SD $=3.95$; range: $0-14)$ and an illiteracy rate of $30 \%(n=59)$. Half of the participants $(52 \%, n$ $=103)$ joined their first armed group voluntarily and 63\% $(n=124)$ were younger than 18 
years when they joined an armed group for the first time. They served on average for 6.76 years $(S D=5.19$, range: $0.3-28)$ in armed groups and belonged to a variety of armed groups and forces. In total, $42 \%(n=84)$ were former members of the foreign armed group Forces Démocratique pour la liberation du Rwanda (FDLR) and 58\% $(n=114)$ of Congolese armed groups including different self-defense militias (so-called Mai-Mai groups), Congrés National pour la Défense du Peuple (CNDP), or the Congolese National Army (FARDC).

\section{Procedure}

All interviews were conducted between March and May 2011 in Goma, in the province of North Kivu in the eastern DRC. In total, 72\% $(n=142)$ of the completed interviews took place at the demobilization camp of the UN and $28 \%(n=56)$ were conducted at a training center for war-affected youth. The demobilization camp is a transition camp for all combatants who leave his or her armed group in the province of North Kivu. We were able to interview all combatants who passed through this demobilization camp at the time of assessment. No former combatant refused participation. Participants, however, stayed only between 20 and 72 hours in the demobilization camp before being sent to welcome centers. In the training center, a one-year vocational training was offered to former (child) soldiers. We interviewed all former combatants who were enrolled in this particular program.

Four clinical psychologists and one psychiatric nurse interviewed all participants with the help of three interpreters, who had all been extensively trained in the diagnostic assessment procedure. Structured interviews were carried out in Kiswahili, Kinyarwanda, or Lingala. The interviewers had standardized the form of assessment by practicing in joint interviews in order to ensure high inter-rater reliability. The translation was discussed in great detail to ensure precision. Each participant was interviewed in a private setting by one interviewer together with an interpreter. The interview took on average 1.5 hours.

The Ethical Review Board of the University of Konstanz, Germany, the Disarmament, 
Demobilization and Reintegration (DDR) department responsible for North Kivu of the UN's mission in the DRC, and the respective Congolese nongovernmental nonprofit organization approved the study. All of the participants gave their informed consent orally. In addition to this oral consent, we asked the respective institutions for permission to interview under-aged combatants, as their caregivers were not available. All participants received financial compensation of about 2 U.S. dollars.

\section{Measures}

The first part of the interview consisted of socio-demographic information (e.g., place and year of birth, as well as educational background). Thereafter, former combatants were interviewed about how they were recruited (forcibly vs. voluntary) and at what age. Although, some authors have argued that the boundaries between forcible and voluntary recruitment are blurred (Wessells, 1997), we relied on the individual combatant's subjective perception of the recruitment type (Hecker, Hermenau, Maedl, Hinkel, et al., 2013). We also asked them questions about their military career, such as their highest received rank and the length of their service.

Committed offenses during combat. In a manner similar to a trauma exposure checklist, we assessed the combatant's violent behavior with the presence of different categories of committed offenses during combat (Crombach \& Elbert, 2014; Hecker, Hermenau, Isele, \& Elbert, 2014). For this, we used a checklist of nine different types of offenses ranging from physical assault to rape or killing (see also Table 1 for more details). This checklist has been successfully used in other studies with Congolese combatants (Hecker, Hermenau, Maedl, Hinkel, et al., 2013; Hecker et al., 2012). The number of times a specific event had been experienced was not assessed, as the distorted memory of many combatants due to trauma-related disorders would render this measure unreliable (Elbert \& Schauer, 2002). Each offense type was coded as 1 (committed) or 0 (not committed). The 
number of different committed offense types was summed to a total score (possible range: 0 to 9). The participants reported on average that they have committed $\mathrm{M}=4.96$ different offense types $(\mathrm{SD}=1.90$, range: $0-9)$.

Intrinsic rewards. The appetitive perception of violence as one form of intrinsic reward for violent behavior was assessed with the Appetitive Aggression Scale (AAS; Weierstall \& Elbert, 2011), which has been validated with over 1.600 ex-combatants and proven to have good psychometric properties in comparable samples from Uganda (Weierstall et al., 2012) and the DRC (Hecker et al., 2012; Hecker, Hermenau, Maedl, Schauer, \& Elbert, 2013). The AAS consists of 15 items regarding the appetitive perception of violence (e.g., "Is it exciting for you if you make an opponent really suffer?", "Once fighting has started do you get carried away by the violence?" or "Is fighting the only thing you want to do in life?"). Participants rated how much they agreed with a given question or statement on a 5-point Likert scale ranging from completely disagree (coded as 0) to completely agree (coded as 4). It is important to note that most of the items of the AAS are based on the definition of the instrumental aggression subtype according to Vitiello and Stoff (1997) and the ICD-10 addiction criteria (WHO, 1992). Additional items were compiled on the basis of interviews with (former) child soldiers about the appetitive perceptions of aggression and violence (Elbert et al., 2010). In the validation study (Weierstall \& Elbert, 2011), the AAS showed good psychometric properties. Cronbach's $\alpha$ coefficient of the sum score was .85 and in a principal-axis factoring analysis all items loaded statistically significantly onto a single factor accounting for $32 \%$ of the total variance. For the analysis, a sum score of all items was computed. It ranged from 0 to 60 . The Cronbach's $\alpha$ coefficient was .89. On average, the participants reported a mean of $24.32(S D=14.14$, range: $0-60)$.

Extrinsic rewards. We assessed extrinsic rewards with a checklist of seven commonly used extrinsic rewards (e.g., "In your unit were you ever given additional money 
as a reward for violent behavior?" or "In your unit were you ever given extra food as a reward for violent behavior?"; see Table 2 for more details). The list of extrinsic rewards was based on previous studies with former members of armed groups in the Great Lakes Region of Central Africa (e.g., Haer et al., 2013) and informal conversations with former combatants during the preparation of the study. Each reward type was coded as 0 (not received) or 1 (received). The number of different extrinsic reward types was summed to a total score (possible range: 0 to 7). The participants reported on average that they have received $M=1.92$ different extrinsic rewards $(S D=1.39$, range: $0-6)$.

\section{Data Analysis}

Before we conducted moderated sequential multiple regression analyses to investigate the prediction of the committed offense types by the AAS and the number of extrinsic rewards, we analyzed the correlations between these variables.

The multiple regression analysis that we conducted included the following control variables: type of recruitment (forcibly recruited is coded as 0 ; voluntarily enlisted as 1) and the age of recruitment (below 18 years old is coded as 0 ; and above 18 years old is coded as 1). In the first step, the regression model included both control variables. In the second step, the number of received extrinsic rewards and the AAS score - as a proxy for intrinsic rewards- were added to the model. Subsequently, the two-way interaction terms between recruitment type and AAS and between recruitment type and the number of extrinsic rewards were added. Finally, the three-way interaction term between recruitment type, AAS score, and the number of received extrinsic rewards was included in the model. To mitigate multicollinearity, the predictor variables were z-standardized for the calculations of the interaction terms. None of the variables deviated significantly from normal distributions. All regression models fulfilled the necessary quality criteria for linear regression analyses. The residuals did not deviate significantly from normality, linearity, and homoscedasticity. The 
REWARDS AND VIOLENCE

maximum Variance Inflation Factor did not exceed 1.2. Hence, we did not need to take multicollinearity into account. All analyses used a two-tailed $\alpha=.05$. Our metric for a small effect size was $f^{2} \geq .02$, for a medium effect $f^{2} \geq .15$, and for a large effect $f^{2} \geq .35$. Data was analyzed with IBM SPSS Statistics Version 21 for MAC.

\section{Results}

\section{Descriptive results}

Table 1 shows the frequency of violent offenses committed by both forcibly recruited and voluntarily enlisted combatants during combat. In general, former combatants reported frequently having assaulted others with a weapon (96\%), followed by mutilating other people (79\%), attacking civilian villages $(77 \%)$ or assaulting others physically $(77 \%)$. The two groups differed significantly in assaulting other person with weapons, in attacking civilian villages and in eating human flesh, with voluntarily enlisted combatants reporting higher levels in these categories. Table 2 displays the number of extrinsic rewards offered to the two groups of combatants. Combatants were most often offered higher ranks $(65 \%)$, alcohol or other drugs (36\%), or money (34\%) as a reward for violent behavior. Voluntarily enlisted combatants reported significantly more often that they were offered a higher rank as a reward.

Table 3 shows the demographic characteristics of forcibly recruited and voluntarily enlisted combatants. The two groups differed significantly in age, years of formal education, the total number of years spent in armed groups, the appetitive perception of violence (assessed with the AAS score) and the received number of extrinsic rewards. Voluntarily enlisted combatants reported to be older, to have more years of formal education, to be active in the armed group for a longer period of time, to have a higher level of appetitive perception of violence, and to have received more extrinsic rewards for aggressive behavior than those who were forcibly conscripted. Table 4 displays the intercorrelations of all variables. 


\section{Associations between intrinsic and extrinsic rewards and committed offenses during combat}

The first regression model, designed to predict the number of committed offenses with the two control variables (age of recruitment and recruitment type) accounted for $10 \%$ of the variability of the committed offense types $\left(\operatorname{adj} . R^{2}=.11, F(2,195)=11.72, \mathrm{p}<.001, f^{2}\right.$ $=.12$ ). After adding the AAS score and the number of extrinsic rewards, the regression model accounted for $30 \%$ of the variance. The change in $R^{2}$ was significant, $\Delta R^{2}=.20, F(2,193)=$ 28.20, $p<.001, f^{2}=.25$. As shown in Table 5 , the main effects of the number of received extrinsic rewards and the AAS score were positively and significantly related to the number of perpetrated offenses. In other words, the more extrinsic or intrinsic rewards a combatant received, the more violent offense types he committed. Age of recruitment was significantly negatively related to the number of committed offenses, i.e. younger combatants perpetrated more different types of offenses than older ones. However, the way in which former combatants were recruited did not have a significant influence. Furthermore, adding the twoway interactions between recruitment type and extrinsic reward types as well as between recruitment type and AAS score did not improve the model further, $\Delta R^{2}=<.01, F(2,191)=$ 0.96, $p=.386, f^{2}<.01$. Neither did the model improve after adding the three-way interaction term between recruitment type, extrinsic rewards, and the AAS score to the regression model, $\Delta R^{2}<.01, F(2,190)=1.14, p<.287, f^{2}<.01$.

\section{Discussion}

Throughout history, it has been argued that one of the many factors for combatants' violent behavior is the possibility of receiving rewards (Keeley, 1996). Most research have been focused on examining the influence of extrinsic rewards on aggressive behavior, i.e. how the behavior of a combatant changes when receiving tangible goods such as money, (extra) food, or alcohol. Little attention has been devoted to explain the influence of intrinsic rewards on 
violent behavior. We operationalize these latter types of rewards by looking specifically at the influence of the appetitive perception of violence: violence in itself becomes enjoyable above and beyond its original instrumental function (Elbert et al., 2010; Hecker et al., 2012). Specifically, we examined the influence of extrinsic as well as these intrinsic rewards in a sample of former combatants from the DRC.

In line with our hypotheses, we found a significant association between both intrinsic and extrinsic rewards with types of committed offenses in our sample of combatants. This is in line with other studies, which reported that aggressive behavior was reinforced by extrinsic rewards (e.g., Humphreys \& Weinstein, 2006; Kruger \& Nesse, 2004; Weekes-Shackelford et al., 2003; Weinstein, 2007) and intrinsic rewards (e.g., Arjona \& Kalyvas, 2012; Wessells, 1997) or both (Haer et al., 2013).

These findings are not only congruent with the idea that instrumental aggressive behavior is often prompted by its anticipated benefit (Kruger \& Nesse, 2004; Shackelford, 2005) but also with the cycle of violence hypothesis, which suggested that violence breeds further violence (Hecker, Fetz, Ainamani, \& Elbert, 2015). Rewards (whether extrinsic or intrinsic) can maintain and perhaps even strengthen this vicious cycle of violent behavior, for example, through anticipated benefits (extrinsic rewards) or the hedonic emotions (intrinsic rewards) that are associated with violent behavior. In this way, our findings may contribute both to a better understanding of the high levels of violence in the ongoing conflict in the DRC, as well as the violence reported in different postwar communities (Catani, Jacob, Schauer, Kohila, \& Neuner, 2008; Saile, Ertl, Neuner, \& Catani, 2014).

Moreover, our results indicate the need for an adjustment of traditional reintegration programs for former combatants. Currently, these programs are rarely evaluated, nor are they adapted to the combatant's needs and they fail to address combatants' aggressive behavior and potential mechanisms that maintain the reinforcement of such behavior (Hoge, 2011; 
Maedl, Schauer, Odenwald, \& Elbert, 2010). In order to increase their effectiveness, these programs would need to address not only the extrinsic but also the intrinsic rewards for acting violently, for instance, by not only focusing on economic aspects of reintegration (e.g., micro-credits, training in manual trades) but also by offering psychological treatment for those that are experiencing a high appetitive perception of violence.

In addition to the above described findings, we discovered significant differences between forcibly conscripted combatants and those who enlisted on a voluntarily basis. Voluntarily enlisted combatants reported on average a higher number of received extrinsic rewards for violent behavior than those who were forcibly recruited. One explanation may be that commanders more often allowed voluntarily enlisted combatants (than forcibly recruited combatants) a share of the loot and thus rewarded their violent behavior with money or goods. In line with previous studies (Hecker, Hermenau, Maedl, Hinkel, et al., 2013; Weierstall et al., 2013) voluntarily enlisted combatants also reported higher levels of intrinsic rewards (i.e., appetitive perception of violence) than forcibly recruited combatants. However, we did not find a significant difference between the two groups concerning the number of different types of committed offenses. Furthermore, our analysis did not reveal a significant influence of the recruitment type on the relation between extrinsic and/or intrinsic rewards and committed violence. At first glance these findings contradicted previous ones (Haer et al., 2013), which indicated a stronger relationship between extrinsic rewards and appetitive perception of violence in former abductees than combatants who joined the armed group on a voluntary basis, and the reverse relationship for intrinsic rewards. However, both studies operationalized intrinsic rewards differently. Haer et al (2013) operationalized it as commitment to unit and organization, while our study focuses on the appetitive perception of violence. The difference in results also suggests a heterogeneity in intrinsic reward types, which requires further research. More importantly, Haer et al. (2013) aimed to explain the 
REWARDS AND VIOLENCE

differential relation of camaraderie and extrinsic rewards on the appetitive perception of violence in forcibly recruited and voluntarily enlisted combatants. With this study, however, we aimed to explain actual violent behavior during combat based on intrinsic and extrinsic rewards. Nonetheless, it remains unclear whether intrinsic and extrinsic rewards indeed play a differential role in reinforcing aggressive and violent behavior in voluntarily enlisted and forcibly recruited combatants. Further studies are needed to shed light on these conflicting findings.

\section{Limitations}

This study has some limitations: first, the cross-sectional study design and the retrospective assessment did not allow the establishment of any form of directionality. Therefore, the reported relations need to be interpreted with caution. For instance, intrinsic and extrinsic rewards might lead to more types of committed offenses, which in turn might increase the likelihood of receiving rewards. In other words, a violent environment, as is the case in the DRC, could generate a vicious cycle of rewards for committing violence and committing violence. Future studies, using larger samples and ideally longitudinal and/or experimental designs are needed to pinpoint its directionality. Second, we used a self-developed measure for assessing extrinsic rewards in this study. We are not able to provide any information on its reliability or validity based on other studies. Consequently, the way in which we assessed this type of rewards might influence our findings. Third, due to our operationalization of intrinsic rewards, i.e. the appetitive perception of violence, we also cannot draw conclusions about the influence of other intrinsic rewards, such as the feeling of being accepted, attaining higher self-esteem and feeling appreciated by others. Additionally, we collected the data in the form of self-reports, which makes it difficult to rule out the influence of social desirability on the given answers. Furthermore, we only examined the linkage between (extrinsic and 
intrinsic) rewards on the types of violence perpetrated by demobilized combatants. It is possible that these former combatants differ significantly from those that are still active. By focusing on this specific linkage, we have (necessarily) ignored other existing factors that might be of influence. For instance, we have omitted factors such as moral beliefs and opportunity structures. It is also possible that the association found between rewards and violence reflects a particular confounding personality trait, such as trait aggression, that not only influences the beliefs regarding rewards but also the actual behavior of the combatant.

\section{Conclusions}

This study provides an empirical examination of the role of extrinsic and intrinsic rewards in understanding violent behavior during conflict. The former consisted of factors such as material rewards, access to sexual partners, increased military rank, whereas the latter refer to the intrinsic appetitive perception of violence. Our findings suggest that both types of rewards play a role in committing violence and atrocities during combat. We therefore suggest that reintegration programs need to address the impact of not only extrinsic rewards but also pay attention to the influence of intrinsic rewards facilitating violent behavior. 
REWARDS AND VIOLENCE

\section{References}

Anderson, C., \& Bushman, B. (2002). Human Agression. Annual Reviews of Psychology, 53, 27-51. doi:10.1146/annurev.psych.53.100901.135231

Archer, J. (1988). The behavioural biology of aggression. Cambridge, UK: Cambridge University Press.

Archer, J. (2009). The nature of human aggression. International Journal of Law and Psychiatry, 32, 202-208. doi:10.1016/j.ijlp.2009.04.001

Arjona, A. M., \& Kalyvas, S. N. (2012). Recruitment into armed groups in Colombia: A survey of demobilized fighters. . In Y. Guichaoua (Ed.), Understanding Collective Political Violence (pp. 143-171). Houndsmills: Palgrave Macmillan.

Bandura, A. (1978). Social learning theory of aggression. Journal of Communication, 28, $12-$ 29. doi:10.1111/j.1460-2466.1978.tb01621.x

Berkowitz, L. (1993). Pain and aggression: Some findings and implications. Motivation and Emotion, 17, 277-293. doi:10.1007/BF00992223

Bushman, B., \& Anderson, C. (2001). Is it time to pull the plug on the hostile versus instrumental aggression dichotomy? Psychological Review, 108, 273-279. doi:10.1037//0033-295X.108.1.273

Buss, D. M., \& Shackelford, T. K. (1997). Human aggression in evolutionary psychological perspective. Clinical Psychology Review, 17, 605-619. doi:10.1016/S02727358(97)00037-8

Card, N. A., \& Little, T. D. (2006). Proactive and reactive aggression in childhood and adolescence: A meta-analysis of differential relations with psychosocial adjustment. International Journal of Behavioral Development, 30, 466-480. doi:10.1177/0165025406071904

Catani, C., Jacob, N., Schauer, E., Kohila, M., \& Neuner, F. (2008). Family violence, war, 
and natural disasters: A study of the effect of extreme stress on children's mental health in Sri Lanka. BMC Psychiatry, 8, 33. doi:10.1186/1471-244X-8-33

Collier, P., \& Hoeffler, A. (2004). Greed and grievance in civil war. Oxford Economic Papers, 56, 563-595. doi:10.1093/oep/gpf064

Crombach, A., \& Elbert, T. (2014). The benefits of aggressive traits: a study with street and former street children in Burundi. Child Abuse and Neglect, 38, 1041-1050, 38, 10411050. doi:10.1016/j.chiabu.2013.12.003

Daly, M., \& Wilson, M. (1996). Homicidal tendencies. Demos, 8, 39-45.

Eisner, M. (2009). The uses of violence: An examination of some cross-cutting issues. International Journal of Conflict and Violence, 3, 40-59.

Elbert, T., Hinkel, H., Maedl, A., Hermenau, K., Hecker, T., Schauer, M., ... Lancaster, P. (2013). Sexual and gender-based violence in the Kivu provinces of the Democratic Republic of Congo: Insights from former combatants. Washington, DC: The World Bank. Retrieved from http://www.logicawb.org/PDFs/LOGiCA_SGBV_DRC_Kivu.pdf

Elbert, T., \& Schauer, M. (2002). Burnt into memory. Nature, 419, 883. doi:10.1038/419883a

Elbert, T., Weierstall, R., \& Schauer, M. (2010). Fascination violence: On mind and brain of man hunters. European Archives of Psychiatry and Clinical Neuroscience, 260, 100-105. doi:10.1007/s00406-010-0144-8

Engen, R. (2008). Killing for their country: A new look at killilogy. Canadian Military Journal, 9, 120-128.

Gat, A. (2000). The Human motivational complex: evolutionary theory and the causes of hunter-gatherer fighting, Part I: Primary somatic and reproductive causes. Anthropological Quarterly, 73, 20-34.

Gibson, J. T. (1991). Training people to inflict pain: State terror and social learning. Journal 
REWARDS AND VIOLENCE

of Humanistic Psychology, 31, 72-87. doi:10.1177/0022167891312006

Glowacki, L., \& Wrangham, R. W. (2013). The Role of Rewards in Motivating Participation in Simple Warfare. Human Nature, 24, 444-460. doi:10.1007/s12110-013-9178-8

Grossman, D. (1995). On killing: The psychological cost of learning to kill in war and society. Boston: Little, Brown and Co.

Haer, R., Banholzer, L., Elbert, T., \& Weierstall, R. (2013). Analyzing the microfoundations of human violence in the DRC - intrinsic and extrinsic rewards and the prediction of appetitive aggression. Conflict and Health, 7, 11. doi:10.1186/1752-1505-7-11

Hecker, T., Fetz, S., Ainamani, H., \& Elbert, T. (2015). The “Cycle of Violence”: Associations between exposure to violence, trauma-related symptoms and aggression findings from Congolese refugees in Uganda. Journal of Traumatic Stress, 28, 448-455. doi:10.1002_jts.22046

Hecker, T., Hermenau, K., Isele, D., \& Elbert, T. (2014). Corporal punishment and children's externalizing problems: A cross-sectional study of Tanzanian primary school students. Child Abuse and Neglect, 38, 884-892. doi:10.1016/j.chiabu.2013.11.007

Hecker, T., Hermenau, K., Maedl, A., Elbert, T., \& Schauer, M. (2012). Appetitive aggression in former combatants-Derived from the ongoing conflict in DR Congo. International Journal of Law and Psychiatry, 35, 244-249. doi:10.1016/j.ijlp.2012.02.016

Hecker, T., Hermenau, K., Maedl, A., Hinkel, H., Schauer, M., \& Elbert, T. (2013). Does perpetrating violence damage mental health? Differences between forcibly recruited and voluntary combatants in DR Congo. Journal of Traumatic Stress, 26, 142-148. doi:10.1002/jts. 21770

Hecker, T., Hermenau, K., Maedl, A., Schauer, M., \& Elbert, T. (2013). Aggression inoculates against PTSD symptom severity - insights from armed groups in the eastern 
DR Congo. European Journal of Psychotraumatology, 4, 20070.

doi:10.3402/ejpt.v4i0.20070

Hoge, C. W. (2011). Interventions for war-related posttraumatic stress disorder. Meeting veterans where they are. JAMA : The Journal of the American Medical Association, 306, 549-551. doi:10.1001/jama.2011.1096

Human Rights Watch. (2014). Democratic Republic of Congo: Ending Impunity for Sexual Violence. Retrieved from https://www.hrw.org/news/2014/06/10/democratic-republiccongo-ending-impunity-sexual-violence

Humphreys, M., \& Weinstein, J. M. (2006). Handling and manhandling civilians in civil war. American Political Science Review, 100, 429-447. doi:10.1017/S0003055406062289

Kalyvas, S. N. (1999). Wanton and senseless? The logic of massacres in Algeria. Rationality and Society, 11, 243-185. doi:10.1177/104346399011003001

Keeley, L. H. (1996). War before civilization: The myth of the peaceful savage. New York, NY: Oxford University Press.

Keen, D. (2000). Incentives and disincentives for violence. In M. Berdal \& D. M. Malone (Eds.), Greed and grievance: Economic agendas in civil wars (pp. 19-41). Boulder: Lynne Rienner Publishers.

Kempes, M., Matthys, W., De Vries, H., \& Van Engeland, H. (2005). Reactive and proactive aggression in children. A review of theory, findings and the relevance for child and adolescent psychiatry. European Child and Adolescent Psychiatry, 14, 11-19. doi:10.1007/s00787-005-0432-4

Köbach, A., \& Elbert, T. (2015). Sensitive periods for developing a robust trait of appetitive aggression. Frontiers in Psychiatry, 6, 144. doi:10.3389/fpsyt.2015.00144

Kruger, D., \& Nesse, R. (2004). Sexual selection and the male: female mortality ratio. Evolutionary Psychology, 2, 66-85. doi:10.1177/147470490400200112 
REWARDS AND VIOLENCE

Littman, R., \& Paluck, E. L. (2015). The Cycle of Violence : Understanding Individual Participation in. Advances in Political Psychology, 36, 79-99. doi:10.1111/pops.12239

Maedl, A., Schauer, E., Odenwald, M., \& Elbert, T. (2010). Psychological rehabilitation of ex-combatants in non-western, post-conflict settings. In E. Martz (Ed.), Trauma rehabilitation after war and conflict (pp. 177-213). New York, NY: Springer Science and Business Media. doi:10.1007/978-1-4419-5722-1

Mottaz, C. (1985). Determinants of Organizational Commitment. Human Relations, 41, 467482.

Nell, V. (2006). Cruelty's rewards: The gratifications of perpetrators and spectators. Behavioral and Brain Sciences, 29, 211-257. doi:10.1017/S0140525X06009058

New York Times. (1999). Sierra Leone Measures Terror in Severed Limbs. Retrieved from http://partners.nytimes.com/library/world/africa/082299sierra-leone.html

Opp, K. D. (1986). Soft incentives and collective action: participation in the antinuclear movement. British Journal of Political Sciience, 16, 87-112. doi:10.1017/S0007123400003811

Palmer, C. T., \& Tilley, C. F. (1995). Sexual access to females as a motivation for joining gangs: An evolutionary approach. Journal of Sex Research, 32, 213-217. doi:10.1080/00224499509551792

Prunier, G. (2009). Africa's World War: Congo, the Rwandan Genocide, and the making of a continental catastrophe. Oxford, UK: Oxford University Press.

Saile, R., Ertl, V., Neuner, F., \& Catani, C. (2014). Does war contribute to family violence against children? Findings from a two-generational multi-informant study in Northern Uganda. Child Abuse and Neglect, 38, 135-146. doi:10.1016/j.chiabu.2013.10.007

Shackelford, T. K. (2005). An evolutionary psychological perspective on cultures of honor. Evolutionary Psychology, 3, 381-391. doi:10.1177/147470490500300126 
Staub, E. (2001). Genocide and mass killing: Their roots and prevention. In D. J. Christie, R. V. Wagner, \& D. D. Winter (Eds.), Peace, conflict and violence: Peace psychology for the 21st century. New Yersey: Prentice Hall.

Staub, E. (2006). Reconciliation after genocide, mass killing, or intractable conflict: Understanding the roots of violence, psychological recovery, and steps toward a general theory. Political Psychology, 27, 867-984. doi:10.1111/j.1467-9221.2006.00541.x

United Nations. (2016). Root Causes of Child Recruitment. Retrieved from https://childrenandarmedconflict.un.org/effects-of-conflict/root-causes-of-childsoldiering/

Valentino, B., Huth, P., \& Balch-Lindsay, D. (2004). Draining the sea: mass killing and guerrilla warfare. The Review of International Organ Izations, 58, 375-407. doi:10.1017/S0020818304582061

Vitiello, B., \& Stoff, D. M. (1997). Subtypes of aggression and their relevance to child psychiatry. Journal of the American Academy of Child and Adolescent Psychiatry, 36, 307-315. doi:10.1097/00004583-199703000-00008

Weekes-Shackelford, V., Shackelford, T., \& Buss, D. (2003). Murder in a lover's triangle. In M. D. Smith \& B. PH (Eds.), New directions in homicide research (pp. 219-231). Washington: Federal Bureau of Investigation.

Weierstall, R., Bueno Castellanos, C. P., Neuner, F., \& Elbert, T. (2013). Relations among appetitive aggression, post-traumatic stress and motives for demobilization: a study in former Colombian combatants. Conflict and Health, 7, 9. doi:10.1186/1752-1505-7-9

Weierstall, R., \& Elbert, T. (2011). The Appetitive Aggression Scale-development of an instrument for the assessment of human's attraction to violence. European Journal of Psychotraumatology, 2, 8430. doi:10.3402/ejpt.v2i0.8430

Weierstall, R., Schalinski, I., Crombach, A., Hecker, T., \& Elbert, T. (2012). When combat 
REWARDS AND VIOLENCE

prevents PTSD symptoms - results from a survey with former child soldiers in Northern Uganda. BMC Psychiatry, 12, 41. doi:10.1186/1471-244X-12-41

Weinstein, J. M. (2007). Inside rebellion. The politics of insurgent violence. Cambridge: Cambridge University Press.

Wessells, M. G. (1997). Child Soldiers. Bulletin of the Atomic Scientists, 53, 32-39.

WHO. (1992). ICD-10 classification of mental and behavioural disorders: Clinical descriptions and diagnostic guidelines. Geneva: World Health Organization.

Wood, R. M. (2010). Rebel capability and strategic violence against civilians. Journal of Peace Research, 47, 601-614. doi:10.1177/0022343310376473 
REWARDS AND VIOLENCE

Table 1

Frequency of violent offenses of forcibly recruited and voluntary enlisted combatants

\begin{tabular}{llll}
\hline & $\begin{array}{l}\text { Forcibly } \\
\text { recruited } \\
(\mathrm{n}=95)\end{array}$ & $\begin{array}{l}\text { Voluntarily } \\
\text { enlisted } \\
(\mathrm{n}(\mathrm{n})\end{array}$ & $\begin{array}{l}\mathrm{Chi}^{2} \\
(\mathrm{n}=103)\end{array}$ \\
& $73(69)$ & $81(83)$ & 1.75 \\
\hline Physical assault & $94(89)$ & $99(102)$ & $4.14^{*}$ \\
Assault with weapon & $10(9)$ & $14(14)$ & 0.82 \\
Sexual assault & $28(27)$ & $27(28)$ & 0.04 \\
Participated in a massacre & $84(80)$ & $74(76)$ & 3.21 \\
Looting & $3(3)$ & $14(14)$ & $6.86^{* *}$ \\
Eating human flesh & $74(70)$ & $85(87)$ & 3.50 \\
Mutilation & $35(33)$ & $45(46)$ & 2.03 \\
Killing someone & $70(66)$ & $84(86)$ & $5.45^{*}$ \\
Attacking civilian villages & & & \\
\hline
\end{tabular}

Note. $C h i^{2}$ : test statistics based on $\mathrm{chi}^{2}$-test. ${ }^{*} p<.05 .{ }^{* *} p<.01$. 
REWARDS AND VIOLENCE

Table 2

Frequency of extrinsic rewards that were offered to the combatants by superiors

\begin{tabular}{llll}
\hline & $\begin{array}{l}\text { Forcibly recruited } \\
(\mathrm{n}=95) \\
\%(\mathrm{n})\end{array}$ & $\begin{array}{l}\text { Voluntarily enlisted } \\
(\mathrm{n}=103) \\
\%(\mathrm{n})\end{array}$ & 2.84 \\
\hline Extra money & $28(27)$ & $40(41)$ & 2.82 \\
Extra food & $23(22)$ & $34(35)$ & 0.02 \\
Other goods & $6(6)$ & $7(7)$ & 0.10 \\
Alcohol or other drugs & $35(33)$ & $37(38)$ & 0.10 \\
Prostitutes or women for sexual activities & $8(8)$ & $10(10)$ & $7.02 * *$ \\
Higher rank & $55(52)$ & $73(75)$ & 1.01 \\
Any other reward & $11(10)$ & $16(16)$ & \\
\hline
\end{tabular}

Note. $C h i^{2}:$ test statistics $\mathrm{chi}^{2}$-test. ${ }^{* *} p<.01$. 
REWARDS AND VIOLENCE

Table 3

Demographic characteristics of forcibly recruited and voluntary enlisted combatants

\begin{tabular}{|c|c|c|c|c|c|}
\hline & \multicolumn{2}{|c|}{$\begin{array}{l}\text { Forcibly recruited } \\
(n=95)\end{array}$} & \multicolumn{2}{|c|}{$\begin{array}{l}\text { Voluntary enlisted } \\
(n=103)\end{array}$} & \multirow[b]{2}{*}{$T$ or $C h i^{2}$} \\
\hline & $M$ or $n$ & $S D$ or $\%$ & $M$ or $n$ & $S D$ or $\%$ & \\
\hline Age & 23.18 & 6.37 & 25.54 & 7.39 & $2.40 *$ \\
\hline Formal education (years) & 3.94 & 3.65 & 5.94 & 4.00 & $3.68 * * *$ \\
\hline Years with armed group & 5.53 & 4.20 & 7.90 & 5.74 & $3.34 * * *$ \\
\hline Age at recruitment & & & & & 0.02 \\
\hline$<18$ & 60 & 63 & 64 & 62 & \\
\hline$>18$ & 35 & 37 & 39 & 38 & \\
\hline Committed offense types & 4.70 & 2.06 & 5.20 & 1.71 & 1.90 \\
\hline AAS Score & 20.68 & 13.67 & 27.68 & 13.78 & $3.58 * * *$ \\
\hline Extrinsic rewards & 1.66 & 1.40 & 2.16 & 1.35 & $2.52 *$ \\
\hline
\end{tabular}

Note. M: Mean, $S D$ : standard deviation, $T$ or $C h i^{2}$ : test statistics based on t-test or chi $^{2}$-test. $* p<.05 . * * * p<.001$. 
Page 29 of 30

Aggressive Behavior

REWARDS AND VIOLENCE

29

$$
\begin{aligned}
& 1 \\
& 2 \\
& 3 \\
& 4 \\
& 5 \\
& 6 \\
& 7 \\
& 8 \\
& 9 \\
& 10 \\
& 11 \\
& 12 \\
& 13 \\
& 14 \\
& 15 \\
& 16 \\
& 17 \\
& 18 \\
& 19 \\
& 20 \\
& 21 \\
& 22 \\
& 23 \\
& 24 \\
& 25 \\
& 25 \\
& 26 \\
& 27 \\
& 28 \\
& 29 \\
& 30 \\
& 31 \\
& 32 \\
& 33 \\
& 34 \\
& 35 \\
& 36 \\
& 37 \\
& 3
\end{aligned}
$$

Table 4

Inter-correlations of all relevant variables $(N=198)$

\begin{tabular}{llllllll}
\hline & 1 & 2 & 3 & 4 & 5 & 6 & 7 \\
\hline 1. Age & 1 & & & & & & \\
2. Formal education (years) & .09 & 1 & & & & & \\
3. Years with armed group & $.59^{* * *}$ & .06 & 1 & & & & \\
4. Age at recruitment & $.71^{* * *}$ & .03 & $.14^{*}$ & 1 & & & \\
5. Committed offense types & $-.28^{* *}$ & .07 & -.08 & $-.30^{* * *} 1$ & & \\
6. AAS Score & $-.16^{*}$ & $.21 * *$ & $<.01$ & $-.25^{* * *} .47^{* * *}$ & 1 & \\
7. Extrinsic rewards & $-.22^{* *}$ & .01 & -.14 & $-.21^{* *}$ & $.36^{* * *}$ & $.25^{* * *}$ & 1 \\
\hline
\end{tabular}

Note. Correlation coefficient: Pearson's $\mathrm{r} ;{ }^{*} p \leq .05,{ }^{* *} p \leq .01,{ }^{* * *} p \leq .001$

John Wiley \& Sons 
REWARDS AND VIOLENCE

Table 5:

Multiple regression analysis for committed offenses

\begin{tabular}{|c|c|c|c|c|}
\hline \multirow[b]{2}{*}{ Predictor variables } & \multicolumn{4}{|c|}{ Committed offenses } \\
\hline & $\mathrm{B}$ & SE of B & $\beta$ & $\mathrm{T}$ \\
\hline \multicolumn{5}{|l|}{ Step 1} \\
\hline Age at recruitment & -0.57 & 0.13 & -.30 & $4.42 * * *$ \\
\hline Recruitment type & 0.26 & 0.13 & .14 & $2.03 *$ \\
\hline \multicolumn{5}{|l|}{ Step 2} \\
\hline Age at recruitment & -0.29 & 0.12 & -.15 & $2.40 *$ \\
\hline Recruitment type & $<0.01$ & 0.12 & $<.01$ & 0.05 \\
\hline AAS score & 0.71 & 0.12 & .38 & $5.78 * * *$ \\
\hline Extrinsic rewards & 0.45 & 0.12 & .24 & $3.77 * * *$ \\
\hline \multicolumn{5}{|l|}{ Step 3} \\
\hline Age at recruitment & -0.29 & 0.12 & -.15 & $2.40 *$ \\
\hline Recruitment type & $<0.01$ & 0.12 & $<.01$ & 0.05 \\
\hline AAS score & 0.73 & 0.12 & .38 & $5.89 * * *$ \\
\hline Extrinsic rewards & 0.43 & 0.12 & .23 & $3.54 * * *$ \\
\hline Recruitment type $X$ extrinsic rewards & -.08 & 0.12 & -.04 & -0.63 \\
\hline Recruitment type X AAS score & .15 & 0.11 & .08 & 1.35 \\
\hline \multicolumn{5}{|l|}{ Step 4} \\
\hline Age at recruitment & -0.29 & 0.12 & -.15 & $2.42 *$ \\
\hline Recruitment type & 0.03 & 0.12 & .02 & 0.23 \\
\hline AAS score & 0.74 & 0.12 & .39 & $5.95 * * *$ \\
\hline Extrinsic rewards & 0.46 & 0.12 & .24 & $3.70 * * *$ \\
\hline Recruitment type $X$ extrinsic rewards & -0.06 & 0.12 & -.03 & -0.49 \\
\hline Recruitment type X AAS score & 0.13 & 0.11 & .07 & 1.14 \\
\hline Recruitment type X AAS score X extrinsic rewards & -0.12 & 0.11 & -.07 & -1.07 \\
\hline
\end{tabular}

Note. $R^{2}=.32, f^{2}=.47, \mathrm{~N}=198, \mathrm{~B}$ : unstandardized regression weight, SE: standard error, $\beta=$ standardized regression weight, $\mathrm{T}$ : t-test statistics. ${ }^{*} p<.05 .{ }^{* * *} p<.001$ 